THE INTERNATIONAL

REVIEW OF RESEARCH IN

OPEN AND DISTANCE LEARNING

\title{
Factors that Impact Student Usage of the Learning Management System in Qatari Schools
}
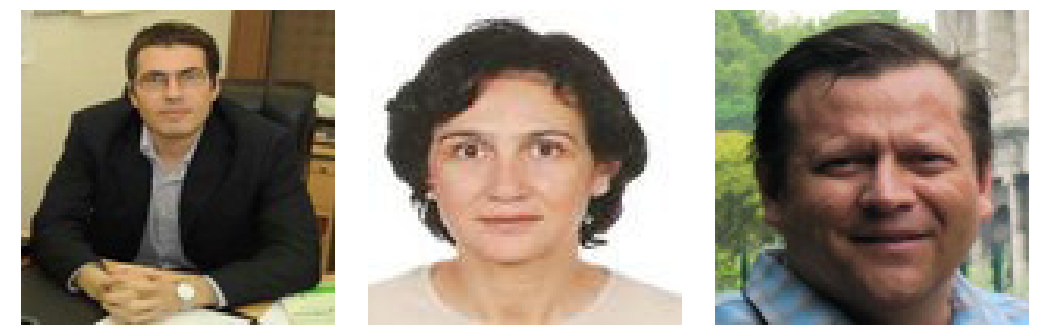

Ramzi Nasser, Maha Cherif, and Michael Romanowski

Qatar University, Qatar

\section{Abstract}

In an attempt to enhance teacher and student performance in school, a learning management system (LMS) known as Knowledge-Net (K-Net) was introduced in Qatari independent schools. (All public schools in Qatar have transformed to independent schools; the independent schools model is similar to the charter school system in North America.) An LMS is a tool that organizes and regulates classroom administrative tasks, supports teachers and students in the teaching and learning process, and informs parents of their children's progress and school activities. Despite the benefits of the LMS, research studies indicate that its use by students has been limited because of a number of manipulative and non-manipulative factors that can influence behavior. This study explores the factors that impact student use of the LMS K-Net in Qatari independent schools. Quantitative data were collected through a questionnaire that was administered to students in 37 schools. A total of 1,376 students responded to the questionnaire. Semi-structured interviews were used to collect qualitative data that helped to confirm the results of the quantitative data and to provide additional insight on students' perspectives regarding the use of the LMS. The results point to a strong relation between ICT knowledge and LMS usage. They suggest that the more ICT knowledge students have, the less prone they are to using the LMS. Attitudinal barriers were not predictive of usage. Student usage was strongly correlated to teacher and parent usage. This study is informative in evaluating LMS usage in Qatari schools.

Keywords: Learning management system; student usage; barriers; knowledge of ICT; Qa$\operatorname{tar}$ 


\section{Introduction}

Information and communication technologies (ICTs) have changed the nature of global interactions and educational practices (Economist Intelligence Unit Limited, 2001). Centered around business (Hollenstein, 2004; Baldwin, Sabourin, \& Smith, 2004), ICT has been adopted in both the public and private spheres and is intensively used in educational institutions (ten Brummelhuis, 2001, as cited in Drent \& Meelissen, 2008). This has created a situation in which ICT affects all educational stakeholders: educators, parents, and students. Although information communication and knowledge-sharing are changing traditional concepts of schooling, the implementation of ICT in schools has been inconsistent (Fahey, 2000). Research suggests that, despite the barriers, online and mobile learning is touted as the newest and best educational practice to remedy the difficulty of access to quality education (Sener \& Stover, 2000).

The current generation of ICT development, known as a learning management system (LMS), is designed to organize and regulate the administrative tasks of schools and other organizations (Esther, 2008). According to Watson and Watson, an LMS provides "functionalities beyond instructional content such as management tracking, personalized instruction and integration across the system" (2007, p. 28). An LMS can effectively support instruction and facilitate learning using an organized "learning structure" to provide support for teaching and learning (Song, 2004; Uzunboylu, Ozdamli, \& Ozcinar, 2006). In addition, an LMS continues well beyond the classroom through emails, discussion groups, student-teacher question-and-answer sessions, the transfer and posting of administrative information, and course content (Kim \& Lee, 2008). Most of these activities are done on a daily basis by students using the computer, Internet, and email, but an LMS facilitates them through a carefully managed system (Cox et al., 2004; Somekh et al., 2002). LMSs help teachers achieve instructional goals through a number of activities that traditionally occur in the classroom. Thus, ICT integration strives to build a learning community among the school stakeholders and partners (Sabherwal \& Newman, 2003). Despite the benefits of LMS, studies have been limited to teacher usage and have only been defined in terms of actual real-time and functional usage.

\section{The LMS in Schools}

An LMS is currently used extensively in Asian countries (Bonk, Lee, \& Reynolds, 2009) and in Gulf Cooperation Council countries (Dutta \& Mia, 2011). The Edunet system, a teaching/learning portal that is described as a comprehensive education information service, was launched in 1996. On the use of this system in the Far East, Chang (2005) indicates that in $2003,80 \%$ of all teachers and $41 \%$ of all students in South Korea had subscribed to Edunet. Thailand has a similar system (Portal for Education) and so does Singapore (Smart Schools). These systems provide curricula through an integrated electronic wireless network that enables teacher, student, and parent interaction.

As a means of managing Jordanian schools that are crowded with Iraqi refugees from the Second Gulf War, the Discovery School Initiative began in 2003 for K-12 public schools in and around the capital city of Amman. The goals of the project were to upgrade tech- 
nology infrastructure, expand computer labs, provide Internet connections, create digital curricula, and support the integration of technology and e-learning resources. At present, there are 100 discovery schools, and the introduction of the system to all 2,300 government schools is underway. In Qatar, Knowledge-Net (K-Net), an educational portal, assists in the development and use of ICT in teaching and learning. It supplies schools with a learning management system to improve the delivery of educational content and accessibility to resources. Although introduced widely throughout the world, the technology does not ensure that it is fully used by stakeholders. Therefore, a need to investigate exists in order to determine whether the stakeholders use the technology as intended, and to what extent.

\section{The LMS in Qatar's Context}

In 2004, the Government of Qatar established the Supreme Council of Information and Communication Technology (ictQATAR) to regulate and encourage the use of technology. ictQATAR is responsible for creating an advanced, knowledge-based society through ICT infrastructure and skills development. One of the ictQATAR initiatives has been to promote ICT in schools. An outcome of this initiative was the development of K-Net as a school-based LMS for data storage, sharing, and data administration that improved content delivery, facilitated resource accessibility, enhanced communication, and expedited administrative tasks. K-Net also connects students, teachers, administrators, parents, and ictQATAR. In 2008, K-Net was initially introduced to 37 schools, and the plan was for the K-Net portal to be introduced to all independent schools (approximately 164 in total) in the State of Qatar.

\section{Barriers to LMS Usage}

The benefits of LMS usage are numerous. However, there are many barriers that prevent their full adoption in schools (Drent \& Meelissen, 2008). Students often complain about their lack of knowledge of ICT and state that teachers provide little support in that area (Drent \& Meelissan, 2008). Some of the student barriers identified by Selim (2007) include instructors' attitudes and teaching styles, student motivation, student technical competency, student-student interaction, ease of access to the technology, infrastructure reliability, and lack of support at the postsecondary level. Likewise, Becker (2000) found the following barriers to technology use: (a) some older teachers were prone to teach using traditional means, (b) novice teachers with limited training were less likely to use the technology, (c) a lack of commitment to a constructivist pedagogy, (d) a lack of available professional development, and (e) a low level of contact between teachers who have little experience using technology. Mulkeen (2003) suggests that infrastructure barriers such as those presented by equipment and processing requirements have raised substantial arguments against their full use, stating that these barriers are not limited to external factors but also include internal ones, such as attitudinal barriers. Some users consider themselves confident and knowledgeable in the use of ICT; whereas, others are more uncertain and hence have a greater propensity to reject the technology in their classrooms (Looker \& Thiessen, 2003).

In recent years, a plethora of studies have examined teacher use of ICT, but little has emerged on student usage. The perceived functionality and usefulness of ICT are key factors in student usage. Pituch and Lee (2006) observed that the strongest influences on student 
use of an LMS were the system characteristics and their perceived functionality. Hayashi, Chen, Ryan, and Wu (2004) confirmed this finding and argued that perceived usefulness and satisfaction could directly influence LMS usage. Furthermore, these researchers found that user satisfaction takes precedence over perceived usefulness in terms of the expected usage. Heath and Ravitz (2001), cited in Gibbs, Dosen, and Guerrero (2009), found that student academic success is related to access to technology. Likewise, a review article on barriers to assistive technologies revealed that funding and technology access appear to be the most pressing barriers (Copley \& Ziviani, 2004). However, Mulkeen's (2003) Irish study found that the increased supply of equipment such as computers, servers, and hubs does not increase the usage of these technologies. ICT context and setting are not only tied to the equipment that exists in schools, there are also organizational, physical/technical, and practical factors that may inhibit implementation (Becker, 2000). For example, the existence of a culture of technology in the workplace encourages its use in schools (Rochelle, Pea, Hoadley, Gordin, \& Means, 2000). School vision, mission, and philosophy also impact the use of technology. Whereas some schools might stress problem-solving, others might consider these technologies remedial methods to teach basic skills. The variation in schools, depending on whether there is a culture of mastery or constructivist problemsolving, characterizes each institution's e-maturity (Morocco \& Zorfas, 1988). Students and other stakeholders indicated that one of the reasons why students lack technological skills is because administrators, teachers, and parents may not be convinced of the benefits of technology in schools or might not think it is integral to the educational process (BrownYoder, 2001).

A large Canadian study showed a direct correlation between fathers' education and students' ownership and use of the home computer and other kinds of technology. Parents who are not educated technologically are less likely to have children who use the Internet and email or who engage in data entry, make spreadsheets, write computer programs, and use graphic programs. Likewise, a US study by Martinez (1994) found that those who have access to technology at home are more likely to use it in school than those who do not. Educated parents are more likely to instill in their children the importance of ICT use (Looker \& Thiessen, 2003).

Teachers also play an important role in influencing students with instructional practices that motivate them to use ICT. Furthermore, student-perceived teacher expectations are strongly associated with ICT usage (Vekiri, 2010). Specifically, when teachers integrate technology into their classroom and encourage students to learn basic skills such as generating spreadsheets, making PowerPoint presentations, and using digital cameras and word processing software, there are fewer barriers to student use of these technologies and increased usage (Gibbs, Dosen, \& Guerrero, 2009). However, barriers extend beyond the external factors that limit direct access to the technology. Other elements, known as manipulative or endogenous factors, include things such as school attendance, attitude, and level of achievement, contribute substantially to student usage (Slavin, Karweit, \& Maddin, 1989). However, these factors have rarely been integrated into studies of impact on usage. 


\section{Manipulative and Non-Manipulative Factors}

A conceptual model has been developed by Ely (1999), Grunberg and Summers (1992), and Mumtaz (2000) to explain factors that impact usage. They distinguish between nonmanipulative and manipulative school factors. Non-manipulative factors are ones that are not influenced by the school, such as the ages of students and teachers, national reform, ministerial funding, and teacher job experience. These factors include the lack of and unreliability of equipment and technical support needed. The second-order barriers include school culture, attitudes, and beliefs, and these manipulative factors are human ones that can be managed and changed. These factors can also be observed and include the attitudes of teachers toward teaching and ICT, the ICT knowledge and skills teachers have, and school ICT policy.

In the further development of these dichotomous factors, Drent and Meelissan (2008) referring to ten Brummelhuis (1995) suggest that these manipulative and non-manipulative factors are interrelated and are particularly dependent on teachers and schools. In other words, there are interrelated school and teacher attributes, such as the age of the teachers (non-manipulative) that influence policy and could impact teacher beliefs. Experienced teachers have a greater influence on policy development and thus are more likely to influence school policymakers and possibly bring about the necessary changes in thinking (manipulative).

The same concept was developed by Snoeyink and Ertmer (2001), including barriers as external (first order) and internal (second order), which reflect the non-manipulative and manipulative respectively. The proposition of this study is that non-manipulative school factors, such as context, norms, teachers, and parents, affect students' usage. This in turn may influence the behavioral intention of students, affecting their beliefs and attitudes. In the current study, we examined student perceptions of the resources at home and at school (a non-manipulative factor), student perceptions of barriers and knowledge (manipulative factors), and attitudes related to barriers and knowledge on usage (a manipulative factor).

\section{Knowledge of the LMS and Usage}

A prevalent discourse in the ICT literature about those who have the knowledge ("haves") and those who lack it ("have-nots") suggests that there is asymmetric ICT distribution in societies or nations with developing economies. The argument goes that the digital divide appears to be a larger social phenomenon and educational problem (Atwell, 2001). Scholars who take part in this discourse also note that more than half of the world's children lack basic ICT resources, and there is widespread agreement on the relevance of ICT in developing economies (Walsham \& Sahay, 2006). The belief is that those who lack this knowledge will never be able to close the gap in technological knowledge and access, and that this new form of illiteracy will be more prevalent and costly to remedy than others. It is argued that those who have ICT knowledge are likely to have an advantage over those who lack it. More importantly, attitudes toward the behavior and how it is perceived could lead to the formation of a behavioral intention. Favorable attitudes and behavioral control result in a positively perceived behavioral outcome and a stronger intention to perform the behavior 
in question.

\section{LMS Usage}

In terms of usage, we shift the concept from being subjective, as in perceived usefulness, to objective (Al-Senaidi, Lin \& Poirot, 2009). We observe specific measures of usage in the number of logins, time of logins, and requests made to the technical staff. Specifically, we examine LMS usage among students as a metric and objective measure. We also define attitudes toward the behavior in terms of barriers, both manipulative (e.g., interest, skills, or knowledge) and non-manipulative factors (e.g., lack of Internet access), hindering students' full use of the ICT system. Knowledge is defined as the level of student skill in various information communication technologies, including email, Internet, PowerPoint, and other utilities. In addition, knowledge includes skills in the use of LMS components such as uploading, downloading, chats, and discussion forums.

\section{Aims of the Study}

This study focuses on student LMS usage. In particular, it centers on student LMS/ICT knowledge and the effect of barriers on that usage. The study explores the following questions.

- How do students respond to questions regarding barriers and knowledge?

- What is the predictive power of manipulative and non-manipulative factors, and what is their relationship to attitudes, subjective norms, and belief systems on LMS usage?

- Are perceived barriers (manipulative or non-manipulative) the main predictors of usage of LMS?

\section{Methods}

\section{Procedure}

Survey and interview questionnaires were the main methods of data collection. The survey data were collected using the online survey collector Survey Monkey ${ }^{\mathrm{TM}}$. Technical staff from the Ministry of the Supreme Council of Information and Communication Technology (ictQATAR) connected the Survey Monkey ${ }^{\mathrm{TM}}$ questionnaire to the K-Net LMS. Once students logged into the LMS, they were prompted to respond to the questionnaire. To increase the number of responses, the researcher met with the project managers (information technology personnel at the schools), introduced the study, and distributed the questionnaire so that the managers became familiar with the type of questions the students were being asked. The project managers who managed the LMS in all 37 schools were instructed to remind students and teachers of the questionnaire. Because many of the project managers also taught the students ICT skills, they were asked to set aside a time for students to respond to questions in class. Project managers regularly reminded teachers to encourage 
their students to respond to the questionnaires. The students (respondents) were reassured that there was no right or wrong response, but that the researchers were seeking their opinions on the different aspects of the LMS and that complete confidentiality would be maintained at all times. A total of 1,376 students responded to the questionnaire.

The questionnaire used in this study examines the two main factors of student-perceived barriers and students' knowledge. It is constructed of statements from previously published questionnaires from the Texas Center for Educational Technology at the University of Northern Texas and item domains established by Kuhlemeier and Hemker (2007). Selected items address knowledge and barriers and have previously been used to evaluate ICT. These items have been used and validated in various contexts by their source authors.

The questionnaire item responses were constructed on a four-point Likert scale from often used $(=4)$ to never used $(=1)$. The attitude subsection of the questionnaire used ratings ranging from strongly agree $(=4)$ to strongly disagree $(=1)$. The questionnaire was printed in English and Arabic on the same form. The English items were translated by a committee cross-translation method widely used to translate an instrument from a source language (English) to a target language (Arabic) (Nasser, 2005). Three translators were asked to translate the items, and the translations were validated by bilingual judges.

\section{Interview Questions}

Qualitative data were acquired through semi-structured interviews with individuals and focus groups. The research team visited five selected schools and conducted interviews with students. The selection of schools was based on student and school usage data.

An announcement about the study was made to the students on the LMS. Five schools responded to the researchers' call for interviews, and a total of 21 students were interviewed. The purpose of these interviews was to gather data related to experiences and perceptions of LMS use. Interviews were conducted using a guide that contained a series of open-ended questions (see Table 1). Based on the participants' responses, probing questions were asked to increase information, allowing us to gain a thorough understanding of the participants' perspectives and the reasoning behind their responses. We identified trends, themes, and patterns (Kreuger, 1988). As new topics developed, focus groups were asked to discuss the issues or express their viewpoint on this new information. The questions asked by the researchers are listed in Table 1. 
Table 1

Interview Questions

Leading Student Questions

1. Have you worked on ICT projects using the LMS?

2. Have you learned a lot using the LMS?

3. What are the things in the LMS that you would like teachers and others to use?

4. What other skills would you like to learn from (about how to use, or in order to use) the LMS?

5. What are the main barriers that you face using the LMS?

The interview with students continued until data saturation occurred. Saturation means that no matter how much more data are collected, there would be no new dimensions or properties to develop further categories. Once saturation was evident, we began to interpret our findings and developed the discussion, backed by the survey data. After a close analysis of participants' responses to the interviews, the information was categorized according to topics predominantly derived from the data. Finally, the findings were merged with the quantitative data into a tightly woven account resembling the reality of LMS usage.

\section{Secondary Data}

As mentioned earlier, the technical provider of the LMS provided the researchers with student LMS usage, and these data were merged with the survey responses. Once a student completed the survey at school, the usage data for that individual included the number of uploaded documents, average student hits (i.e., logins), duration of logins, and requests made to the help desk run by the Information Technology School Support Team. Data on usage were also collected for teachers, administrators, and parents. A correlational analysis was performed between all stakeholders (students, teachers, and parents) to determine association patterns between the different stakeholders, providing further evidence and supporting latent correlations. These data are available and easily provided by Maloumatia, a publicly funded company that developed the learning management system Knowledge-Net (K-Net). The correlations provide general information on usage.

\section{Variables and Limitations}

Two independent variables were conceptualized in this study, namely perceived knowledge and barriers (for knowledge items see Table 2, items 1-15; for barrier items see items 16-21). The dependent variable is student usage of the LMS. Our intent was to build a path model linking these variables as attitudes and barriers to the knowledge of students; however, it was nearly impossible to operationally link usage with their responses to the questionnaire as the LMS (K-Net) does not track usage among end users. Therefore, the researchers used school usage rather than student usage when conducting the regression analyses. Other stakeholders, teachers and parents, are equally important to the effective use of the LMS. These will be included in a fully developed model once the results of the current study are analyzed. 


\section{Statistical Analysis}

To examine the data, several statistical methods were used. The first analysis involved descriptive statistics based on the responses to the items on the questionnaire. In the second analysis, we ran a correlation to determine the association between student and parent usage and between student and teacher usage. Third, we ran an exploratory and confirmatory factor analysis to obtain reliability and validity measures for the knowledge and barriers items of the questionnaire. The explanatory factor analysis was conducted to examine the factor structure of the survey instrument. To determine reliability, we evaluated the internal consistency of the items representing each factor using Cronbach's alpha.

The items in the student questionnaire were factor analyzed using principle component analysis with unities in the diagonal, an Eigen cutoff value of 1.0, and a varimax rotation (Tabachnick \& Fidell, 2007) to validate the factors formed before the two main factors of knowledge and perceived barriers to student usage. To validate the reliability of each scale, we calculated using a Cronbach's alpha. Finally, three regression analyses were performed. The first analysis addressed the ICT/LMS knowledge and barriers as predictor variables. We separated the knowledge scale into two variables and ran a second and third regression analysis based on them. The second regression analysis addressed ICT knowledge and barriers as predictor variables on usage. The third regression analysis addressed the knowledge of LMS and barriers as a predictor variable on usage. The regression analyses were performed using the school as the unit of analysis. Because the usage was provided for each school at an aggregate level, student-rated barriers and knowledge were averaged for each school such that each was assigned its measure based on students' average ratings for these variables.

\section{Results}

\section{Descriptive Findings}

In terms of knowledge, most of the students who responded to the questionnaire used ICT and LMS technologies to communicate and work on specific applications, as evident from items 1 to 15. Students indicated there were few barriers in terms of the availability of technologies. However, they argued that there was little time at school to use the LMS. In addition, there was an equal number of respondents who felt that the LMS was overly difficult to use or who did not know how to use it. 
Table 2

The Survey Questionnaire: Responses and Percentages

\begin{tabular}{|c|c|c|c|c|}
\hline $\begin{array}{l}\text { How often do you do the following } \\
\text { activities? }\end{array}$ & Often & Sometimes & Rarely & Never \\
\hline $\begin{array}{l}\text { Use the computer for class work or home- } \\
\text { work }\end{array}$ & $421(37.2)$ & $508(44.9)$ & $148(13.1)$ & $55(4 \cdot 9)$ \\
\hline Use the Internet for homework & $367(32.4)$ & $447(39.5)$ & 225(19.9) & $93(8.2)$ \\
\hline Communicate through email & $461(40.7)$ & $278(24.6)$ & 205(18.1) & 188(16.6) \\
\hline & & & $220(19.4)$ & 202(17.8) \\
\hline Participate in chats on the Internet & $412(36.4)$ & 298(26.3) & & \\
\hline Find information on the Internet & $606(53.5)$ & $370(32.7)$ & $107(9.5)$ & $49(4 \cdot 3)$ \\
\hline Upload files to the Internet & $441(39.0)$ & $365(32.2)$ & 207(18.3) & $119(10.5)$ \\
\hline Make a PowerPoint presentation & $357(31.5)$ & $378(33.4)$ & $272(24.0)$ & 125(11.0) \\
\hline Use graphics in a PowerPoint presentation & $498(44.0)$ & $341(30.1)$ & $189(16.7)$ & $104(9.2)$ \\
\hline Use sound in a PowerPoint presentation & $330(29.2)$ & $327(28.9)$ & $310(27.4)$ & $165(14.6)$ \\
\hline
\end{tabular}

How often do you use the LMS for each of the following activities?

$\begin{array}{lllll}\text { Group projects } & 319(28.2) & 380(33.6) & 235(20.8) & 198(17.5) \\ \text { Research } & 468(41.3) & 362(32.0) & 164(14.5) & 138(12.2) \\ \text { Homework } & 32(38.2) & 371(32.8) & 176(15.5) & 153(13.5) \\ \text { Communicate with your teacher } & 534(47.2) & 259(22.9) & 204(18.0) & 135(11.9) \\ & & & & \\ \text { Get school grades information } & \text { 266(23.5) } & 309(27.3) & 245(21.6) & 312(27.6)\end{array}$


To what extent do you agree with this statement?

\begin{tabular}{|c|c|c|c|c|}
\hline & $\begin{array}{l}\text { Strongly } \\
\text { Agree }\end{array}$ & Agree & Disagree & $\begin{array}{l}\text { Strongly } \\
\text { Disagree }\end{array}$ \\
\hline I don't know how to use K-Net. & $190(16.8)$ & $217(19.2)$ & 186(16.4) & $539(47.6)$ \\
\hline $\mathrm{K}-\mathrm{Net}$ is too hard to use. & $169(14.9)$ & $223(19.7)$ & $206(18.2)$ & $534(47.2)$ \\
\hline $\begin{array}{l}\text { I do not have a computer at home that I } \\
\text { can use. }\end{array}$ & $205(18.1)$ & $96(8.5)$ & $68(6.0)$ & $763(67.4)$ \\
\hline My parents do not want me to use K-Net. & $159(14.0)$ & $138(12.2)$ & $101(8.9)$ & $734(64.8)$ \\
\hline I do not have Internet access at home. & $198(17.5)$ & $99(8.7)$ & $69(6.1)$ & $766(67.7)$ \\
\hline $\begin{array}{l}\text { We do not have time during school hours } \\
\text { to use K-Net. }\end{array}$ & $236(20.8)$ & $289(25 \cdot 5)$ & 282(24.9) & $325(28.7)$ \\
\hline
\end{tabular}

\section{Quantitative Findings}

The first set of analyses conducted included correlations between parent and student usage and teacher and student usage. This analysis was based on the secondary data provided by the developer of the LMS. Usage was a calculated variable that included the number of uploaded documents, average student hits, and average teacher hits. The correlation between average student hits and parent usage was $r=0.51, p<0.001$. The correlation between the student and teacher usage was $r=0.48, p<0.01$. The correlation between parent and teacher usage was low, only $r=0.06$. 
Table 3

Variance Explained by Each of the Factors

\begin{tabular}{cllllll}
\hline Component & \multicolumn{2}{l}{ Initial Eigen Values } & \multicolumn{3}{c}{ Extraction Sums of Squared Loadings } \\
\cline { 2 - 6 } & $\begin{array}{c}\text { Total } \\
\text { variance }\end{array}$ & $\begin{array}{l}\text { Cumulative } \\
\%\end{array}$ & Total & $\begin{array}{l}\text { \% of } \\
\text { variance }\end{array}$ & $\begin{array}{l}\text { Cumulative } \\
\%\end{array}$ \\
\hline 1 & 5.192 & 24.723 & 24.723 & 5.192 & 24.723 & 24.723 \\
\hline 2 & 3.034 & 14.446 & 39.169 & 3.034 & 14.446 & 39.169 \\
\hline 3 & 1.973 & 9.397 & 48.566 & 1.973 & 9.397 & 48.566 \\
\hline 4 & 1.342 & 6.393 & 54.959 & 1.342 & 6.393 & 54.959 \\
\hline 5 & 1.130 & 5.381 & 60.340 & 1.130 & 5.381 & 60.340 \\
\hline
\end{tabular}

The next analysis was confirmatory factor analysis. This included all of the items of the questionnaire. We expected a two-factor structure. The minimum factor-loading criterion was set to 0.45 (Hair, Black, Babib, Anderson, \& Tatham, 2006); items loading below 0.40 were not used in the interpretation. The first two factors accounted for $39.17 \%$ of the total variance (see Table 3). The items were roughly clustered into the two conceptualized categories, knowledge of ICT/LMS (factor 1) and perceived barriers (factor 2). Factor 3 included sub-knowledge items concerning student knowledge of the LMS. Factor 4 included the items "communicated through email" and "participate in chats on the Internet" (See Table 4). Factor 5 included the ICT knowledge item "use of sound in the PowerPoint presentation."

To determine the reliabilities of the factors and to assess their internal consistency, we used Cronbach's alpha. The three scales that appeared in the factor structures had a meritorious internal consistency (Cronbach's alpha $\geq 0.8$ ). For the items in the first factor (items 1 to 14 , namely, knowledge of ICT/LMS), a Cronbach's alpha of 0.85 was obtained. For the second factor (items 16-21), a Cronbach's alpha of 0.81 was obtained. The scale was scored by adding the rating of all of the items and dividing that total by the number of items. The items of the two scales proved to be appropriate and applicable to a sample of Qatari students.

\section{Regression Analysis}

A linear regression analysis was performed using the mean score for the student knowledge scale. The mean score for the perceived barriers was regressed on student LMS usage as the dependent variable. The regression model indicated that the overall relationship between the independent variables and student usage was nearly significant at $F(2,7)=4.25, p<$ 0.06, with an $R$-squared of 0.55 . This high variance in the model suggests that there was a strong inverse relation between the ICT/LMS knowledge on usage. Hence, we broke down the knowledge of ICT/LMS into two variables, knowledge of ICT and knowledge of LMS, and ran two separate regressions. 
Table 4

Principal Component Analysis

\begin{tabular}{llllll}
\hline & \multicolumn{5}{c}{ Components } \\
\hline & 1 & 2 & 3 & 4 & 5 \\
\hline Use the computer for class work or homework & .534 & -.151 & .173 & -.394 & .303 \\
\hline Use the Internet for homework & .567 & -.167 & .162 & -.351 & .397 \\
\hline Communicate through email & .458 & -.237 & .287 & .551 & .149 \\
\hline Participate in chats on the Internet & .540 & -.166 & .285 & .494 & .141 \\
\hline Find information on the Internet & .561 & -.268 & .159 & -.183 & .334 \\
\hline Upload files to the Internet & .521 & -.197 & .301 & .327 & .097 \\
\hline Make a PowerPoint presentation & .592 & -.259 & .329 &.- .231 & -.367 \\
\hline Use graphics in a PowerPoint presentation & .575 & -.297 & .376 & -.244 & -.375 \\
\hline Use sound in a PowerPoint presentation & .632 & -.136 & .210 & -.125 & -.461 \\
\hline Group projects & .628 & .067 & -.453 & -.109 & .038 \\
\hline Research & .603 & -.029 & -.544 & -.079 & .143 \\
\hline Homework & .597 & -.025 & -.515 &.- .114 & .149 \\
\hline Communicate with your teacher & .544 & .170 & -.210 & .112 & -.285 \\
\hline Get school grades information & .562 & .036 & -.413 & .131 & -.164 \\
\hline Chat or email with friends & .585 & -.050 & -.311 & .414 & -.028 \\
\hline I don't know how to use K-Net & .221 & .612 & .351 & .001 &. .113 \\
\hline I do not have a computer at home that I can use & .282 & .720 & .018 & -.013 & -.095 \\
\hline My parents do not want me to use K-Net & .273 & .684 & .041 & .020 & -.025 \\
\hline I do not have Internet access at home & .251 & .721 & -.026 & -.034 & -.116 \\
\hline We do not have time during school hours to use K-Net & .189 & .551 & .145 &.- .101 & .131 \\
\hline K-Net is too hard to use & .214 & .626 & .345 & .055 & .155 \\
\hline & & & & & \\
\hline
\end{tabular}

In a second and third regression (see Table 5), we used a measure that separately addressed the ICT and the LMS knowledge items respectively. LMS knowledge appeared as the third factor in the item reduction analysis. The $R$-squared for the second regression was 0.56. Although the variance was meritorious, the regression model showed that the overall relationship between the independent variables and student usage was insignificant at $F(2,7)=4.3, p>0.05$. The knowledge of ICT was significantly and inversely related $(p<0.05)$ to student usage. Barriers were entered second in the regression and had a non-significant relation (see Table 5 ). 
In the third and final quantitative analysis we carried out a linear regression. The $R$-squared was 0.17 , and the model was not significant at $F(2,7)=0.72, p>0.05$. There was no significant relation between LMS knowledge and usage and barriers and usage.

Table 5

Regression Using Barriers and LMS and ICT Dimensions Separately in Two Regression Models

\begin{tabular}{llllll}
\hline Model & \multicolumn{2}{l}{$\begin{array}{l}\text { Unstandardized } \\
\text { coefficients }\end{array}$} & \multicolumn{2}{l}{$\begin{array}{l}\text { Standardized } \\
\text { coefficients }\end{array}$} & \\
& & $\begin{array}{l}\text { Std. } \\
\text { Error }\end{array}$ & Beta & $t$ & Sig. \\
\hline (Constant) & 132.36 & 69.353 & & 1.908 & .098 \\
\hline ICT/LMS Knowledge & -73.144 & 25.156 & -.830 & -2.908 & .023 \\
\hline Barriers & 44.079 & 28.801 & 0.437 & 1.530 & .170 \\
\hline & & & & & \\
\hline (Constant) & 157.82 & 74.815 & & 2.109 & .073 \\
\hline ICT Knowledge & -70.234 & 23.936 & -.787 & -2.934 & .022 \\
\hline Barriers & 32.491 & 27.061 & .322 & 1.201 & .269 \\
\hline & & & & & \\
\hline (Constant) & 26.855 & 74.575 & & .360 & .729 \\
\hline LMS Knowledge & -22.572 & 19.005 & -.440 & -1.188 & .274 \\
\hline Barriers & 22.292 & 37.400 & .221 & .596 & .570 \\
\hline
\end{tabular}

\section{Qualitative Analysis Results}

The analysis of qualitative data shows that students' thoughts about and attitudes toward the use of LMS were not particularly positive. Some of them reported that while the tool could be useful to establish connections between teachers, learners, and administrators, there were technical challenges that limited students' use of some of the features. Several students stated that the LMS portal had few features to make it more attractive or useful than other Web sites. A statement by a student illustrates this point: "LMS has no peculiar aspect that pushes our teachers to use it." In addition, some respondents were not convinced of the necessity of the tool.

When asked whether they used the LMS, many students answered that they did not use it often. One student explained that this was due to the fact that

most teachers never asked or required us to use it, since students were not rewarded for its use-many students may feel it is a resource which they could get through 
other means-some teachers put resources [there], but nothing I needed.

The fact that students did not use the LMS does not seem to be due to a lack of knowledge of how to use it. Most students stated that they had the skills needed to effectively use the LMS.

However, many respondents stressed that they were more interested in using technology for entertainment (games) and communication between peers than for educational purposes. In fact, students who reported using the LMS specified that they used the discussion corner more often than any other feature. One of the students indicated that "the good thing about the LMS is that you can find your friends [that is, classmates] and you can communicate with them." One possible explanation for low student use of the LMS is the lack of teacher encouragement to use it. Students stated that the use of the LMS tended to be limited to the IT class, which may indicate that teachers do not take advantage of its many features.

With regard to the challenges they faced using the LMS, students expressed frustration and negative computing experiences. Nearly every student user had, at one time or another, experienced frustration caused by a very slow computer, the LMS crashing, or the loss of important work. One issue that was clear throughout the data collected was the concern and frustration with technical problems. The dominant issue was the speed of the server. The LMS is linked to the government's educational server system, and all the students expressed concern that the system was slow. In addition, the system automatically logs out a user if the computer is idle for more than 20 minutes. Students described becoming frustrated waiting for the LMS to execute a command, only to have the system automatically log them out before it could do so.

Another challenge faced by students was parents' attitudes toward the LMS and their skill in using it. Students stated that some parents did not allow their children to use the Internet because they did not trust its content and because they had a poor overall understanding of parental controls on web browsers. In addition, most students reported that their parents rarely checked their work on the LMS because they did not know how to, or they felt it was too challenging for them to learn. In support of the qualitative findings, there was a strong correlation between parent and student usage in the secondary data.

\section{Discussion}

This study examined student usage of the LMS in Qatar. The LMS has been introduced to 37 independent schools in the country. The correlation analysis on usage, obtained from secondary data of the 37 schools, indicated that there was a strong correlation between parent and student usage. There was also a strong correlation between teacher and student usage but a weak correlation between teacher and parent usage. According to some students, the teachers did not require the students to use the system. However, teachers at 
a recent workshop reported a positive sense of LMS usage and stated that there were excellent champion teachers (school-designated teachers who have used the K-Net system extensively and have been honored by ictQATAR as K-Net proficient) in specific independent schools who had served as role models and mentors. One school boasted about a champion teacher who recently won a new laptop in a LMS (K-Net) competition. They reported that there were several successes worth mentioning. One teacher stated that in one of the schools, students produced a school magazine, interviewed the principal and their favorite teachers, and then uploaded the magazine onto the LMS. Another teacher explained that students in one school reported active use of the LMS (K-Net), where the teachers required students to use it twice a week during the IT session. Students used the discussion corner to answer teacher-posted questions and to respond to other students' comments or postings. They participated in school and class competitions and games through K-Net, and winners were given an award during a school ceremony to encourage other students to use the LMS. Students also uploaded information and pictures of projects they had prepared for classes. Another interesting use of K-Net was the "stories written by students" on "Students' Voice," a section of K-Net. Students copied stories they had written and uploaded them to the LMS to share them with the school. Students then voted for the best story, and a prize was given to the author, whose name was announced on the LMS (K-Net). Students also recorded themselves singing, reading a poem, or telling a story and uploaded these videos to the LMS (K-Net). The last use mentioned was part of a school-wide competition to find "K-Net Stars" (i.e., those students who used K-Net most) and reward them.

While these reflections were made by teachers after the study period, they also indicated that students not required by their teachers to use the system were less likely to use it. However, when teachers built activities in and around the LMS with a number of benefits and rewards, the students were motivated to use the LMS. In addition, teachers noted that parents did not encourage their children to use the Internet, as indicated by the qualitative interviews. Students expressed concern that their parents were not actively participating in the LMS. Looker and Thiessen (2003) made the same observations in regard to use. Children whose parents were not engaged in ICT, specifically the aspects that concerned their children's schoolwork, were less likely to use the ICT system than students whose parents were more involved. Qualitative data indicated that some parents did not allow their children to use the Internet for fear that their children would be corrupted. Qatar is a conservative Muslim society with many restrictions on the media and Internet access (Romanowski \& Nasser, 2010), and thus students are more likely to develop ICT skills and knowledge if they receive encouragement from their parents (Vekiri \& Chronaki, 2008; Vekiri, 2010).

There appear to be no incentives to use the LMS in the current school system, with the exception of some champion schools. School policy should hence develop a system of rewards or obligations to motivate the students to use the LMS and possibly provide refresher courses for teachers to help them understand the system's features. It is well established that teachers who set achievement expectations in class are as likely as parents to influence students, and their reluctance to use the system might impact student adaptation and serve as a barrier to full usage of the LMS (Jones \& Dindia, 2004). Currently, students may see 
that teachers do not require them to use it, and parents will not follow through because of their fears of what is on the Internet. Teachers are already dealing with a tremendous workload as a result of recent Qatari reforms and may not have time to learn about the LMS or push students to use it (Nasser \& Romanowski, in press). On top of all this, the school system does not currently invest much money in ICT, nor does it integrate it into the curriculum (Bauer \& Kenton, 2005).

The findings of this study suggest that the items on the scales were standard items used in studies to assess knowledge and barriers. The factor analysis results demonstrated two scales, perceived barriers and knowledge of ICT/LMS. The sub-factor of LMS knowledge was also found.

The regression analysis findings demonstrated that knowledge of ICT/LMS was significantly related to usage. When separating knowledge of ICT and knowledge of LMS, knowledge of ICT was the main variable that significantly predicted usage. This was an inverse relationship, that is higher levels of knowledge were associated with less use of the LMS in schools. School children in California and Israel reported that computer knowledge was associated with playing computer or interactive games rather than problem-solving (Baek \& Freehling, 2007; Nachmias, Mioduser \& Shemla, 2001). Simply stated, those with basic ICT knowledge are less likely to use the LMS. This implies that it may be beneficial to encourage LMS usage in the early grades to allow greater integration of the technology in the classroom. These systems could also easily adopt games for learning for the young schoolchildren (Morgan \& Kennewell, 2005).

Concomitant with these findings are those from France, which revealed that the level of ICT knowledge (lower than expected) produced acceptable results on very basic skills, and that secondary students experienced difficulties on tasks that required deeper knowledge (Tort, Blondel, \& Bruillard, 2008). Considering usage among students, Bernstein (1997) highlighted that "computing is more than a set of skills, it is a culture." The acceptance of Internet culture increases access to various forms of ICT knowledge, and this is one aspect of readiness. The use of Facebook or the LMS forces users to learn new concepts and jargon that may be difficult to absorb (such as old words with new meanings, like icons and windows, and new words, taskbar). Those who have already mastered the language (concepts) may not consider the LMS in Qatar to be very entertaining and thus are less likely to use it. The skills needed to utilize the LMS are beyond simple word processing skills and may require new teachers to grasp computer language and culture that some of those working in the school system could resist in light of the current national reform sweeping all Qatari schools. This reflects a low e-maturity level in school staff and possibly an asymmetry between student knowledge and the ICT knowledge being integrated and used in the traditional classroom. Students may be unchallenged by the ICT/LMS usage and, therefore, use their preferred infotainment applications. Teachers could use this aspect of students' tastes to develop an interest in educational technologies.

It can easily be argued that the findings of this study are not entirely positive. However, there is sufficient evidence to believe that the LMS should be further developed within 
schools in Qatar. Anecdotal evidence from teachers (see above) suggests that the majority of them welcome the LMS. They believe that there is room for improvement, indicating the need for a system of rewards and incentives to encourage its successful implementation. Furthermore, most of the teachers believe that they will use it more in the future. The study was likely conducted too early in the LMS implementation (only one year after its introduction) to obtain a fully accurate picture. It is also apparent that the basic self-rated ICT knowledge among students is negatively related to LMS usage. Teachers could easily utilize the skills of students with a high level of ICT knowledge to create incentives and motivators for them to use the LMS. Perhaps it is too early for its wide implementation in all schools. As of 2010, the LMS (K-Net) was given to the Supreme Education Council (SEC), a permanent body representing the end users of the education system (such as employers and higher education institutions) and responsible for setting national education policy (Brewer, Augustine, Zellman, Ryan, Goldman, Stasz, \& Constant, 2007).

The SEC is currently calling for tenders to upgrade the K-Net system applications as well as for a new company to train teachers, students, and parents. The results of the current study could aid teachers in developing programs for students with existing knowledge of ICT. A constructivist approach to LMS engagement is suitable for encouraging students and furthering the use of such systems to promote learning (Richardson, 2004).

There are a number of limitations that the study did not address. Several external factors were not taken into account, including curriculum issues, language barriers, general structural changes, and the work burden of teachers at schools in Qatar (Nasser \& Romanowski, in press). All of these hinder the full usage of the LMS. We argue that for the LMS to succeed, policy must be established with carefully planned directives, schools must call for greater teacher accountability and integration of the national Qatar ICT standards, and a system of teacher and student promotions must be implemented. Further, it must be recognized that students might be less motivated to use these technologies to engage in academic work when other traditional means are as viable to do so. It is recommended that a further follow-up study should be conducted to examine usage among teachers, students, and parents two or three years down the road. Lastly, as various approaches might be successful in different contexts, we suggest that the LMS should be implemented in schools in a customized way to find out what works and what does not.

In closing, due to the rapid technological changes taking place in society, many students might consider the LMS to be boring and "backward" (Anderson \& Blackwell, 2004). Future studies suggest that mobile devices, such as tablets, personal digital assistants (PDAs), and smart phones, and the use of different modes of communication such as SMS messaging, are the way of the future. These new technologies and programs require ongoing staff training. The LMS might need to adapt to catch up to popular technology to become more usable for future students. 


\section{Acknowledgement}

This study has been partially funded by an ictQATAR Grant (Grant \# QUEX SCICT o9 10 11) and Qatar University Internal Grant (Grant \# QUDF-EDU-10 11 4). 


\section{References}

Al-Senaidi, S., Lin, L., \& Poirot, J. (2009). Barriers to adopting technology for teaching and learning in Oman. Computers \& Education, 53, 575-590.

Anderson, P., \& Blackwell, A. (2004). Mobile and PDA technologies and their future use in education (TechWatch report). Retrieved from http://www.jisc.ac.uk/whatwedo/ services/techwatch/reports/horizonscanning/hs0403.aspx

Atwell, P. (2001). Comment: The first and second digital divide. Sociology of Education, 74(3), 252-259.

Baldwin, J. R., Sabourin, D., \& Smith, D. (2004). Firm performance in the Canadian food processing sector: The interaction between ICT, advanced technology use and human resource competencies. In OECD (Ed.), The economic impact of ICT: Measurement, evidence and implications (pp. 153-181). Paris: OECD.

Baek, E., \& Freehling, S. (2007). Using internet communication technologies by low-income high school students in completing educational tasks inside and outside the school setting. Computers in the Schools, 24(1/2), 33-55.

Bauer J., \& Kenton, J. (2005). Toward technology integration in the schools: Why it isn't happening. Journal of Technology and Teacher Education, 13(4), 519-546.

Becker, H. J. (2000). Access to classroom computers. Communications of the ACM, 43(6), $24-25$.

Bernstein, D. (1997, February/March). Computing, diversity and community: Fostering the computing culture. Proceedings of the 28th SIGCSE Technical Symposium on Computer Science Education. San Jose, CA.

Bonk, C. J., Lee, M. M., \& Reynolds, T. H. (Eds.) (2009). Preface. A special passage through Asia e-learning. Chesapeake, VA: AACE, 2009.

Brewer, D. J., Augustine, C. H., Zellman, G. L., Ryan, G. W., Goldman, C. A., Stasz, C. \& Constant, L. (2007). Education for a new era: Design and implementation of K-12 education reform in Qatar. Rand Corp: Santa Monica, CA. Retrieved from http:// www.rand.org/pubs/monographs/MG548/

Brown-Yoder, M. (2001). The digital divide. Learning and Leading with Technology, $28(5), 10-13,50-51$.

ten Brummelhuis, A. C. (1995). Models of educational change: The introduction of computers in Dutch secondary education (Doctoral dissertation). University of Twente, Enschede. 
Chang, K. (2005). Technologies in mathematics education in Korea. Advanced Technology Council in Mathematics. Retrieved from http://www.atcminc.com/mDevelopment/ShortArticleSeries/Korea/7Korea.html

Copley, J., \& Ziviani, J. (2004). Barriers to the use of assistive technology for children with multiple disabilities. Occupational Therapy International, 11, 229-243.

Cox, M., Webb, M., Abbott, C., Blakeley, B., Beauchamp, T., \& Rhodes, V. (2004). A review of the research literature relating to ICT and attainment. London: Becta.

Drent, M., \& Meelissen M. (2008). Which factors obstruct or stimulate teacher educators to use ICT innovatively? Computers \& Education, 51, 187-199.

Dutta, S. \& Mia,I (2011). The global information technology report 2010-2011. Geneva: World Economic Forum. Retrieved from http://www3.weforum.org/docs/WEF GITR Report 2011.pdf

Economist Intelligence Unit Limited. (2001). E-readiness rankings. New York: EIU.

Ely, D. (1999). Conditions that facilitate the implementation of educational technology innovations. Educational Technology, 39(26), 23-27.

Esther, S. (2008). One-stop shopping with learning management systems. T H E Journal, 35(6), 18-20.

Fahey, D. M. (2000). Blackboard course info: Supplementing in-class teaching with the Internet. History Computer Review, 16(1), 29-37.

Gibbs, M., Dosen, A., \& Guerrero, R. (2009). Bridging the digital divide: Changing the technological landscape of inner-city Catholic schools. Urban Education, 44, 11-29.

Grunberg, J., \& Summers, M. (1992). Computer innovation in schools: A review of selected research literature. Journal of Information Technology for Teacher Education, $1(2), 255^{-276 .}$

Hair, J., Anderson, R., Tatham, R., \& Black, W. (1998). Multivariate dataanalysis (5th ed.). Englewood Cliffs, NJ: Prentice-Hall.

Hayashi, A., Chen, C., Ryan, T., \& Wu, J. (2004). The role of social presence and moderating role of computer self efficacy in predicting the continuance usage of e-learning systems. Journal of Information Systems Education, 15(2), 139-154.

Heath, M., \& Ravitz, J. (2001, June). Teaching, learning and computing: What teachers say. Paper presented at the World Conference on Educational Multimedia, Hypermedia \& Telecommunications, Tampere, Finland.

Hollenstein, H. (2004). Determinants of the adoption of information and communication 
technologies (ICT): An empirical analysis based on firm-level data for the Swiss business sector. Structural Change and Economic Dynamics, 15, 315-342.

ictQATAR (2009). Qatar's ICT landscape 2009. Retrieved from http://www.ictqatar.qa/ landscape2009/index en.htm.

Jones, S., \& Dindia, K. (2004). A meta-analytic perspective on sex equity in the classroom. Review of Educational Research, 74(4), 443-471.

Kim, S. W., \& Lee, M. G. (2007). Validation of an evaluation model for learning management systems. Journal of Computer Assisted Learning, 24(4), 284-294.

Kreuger, R. A. (1988). Focus groups: A practical guide for applied research. London: Sage.

Kuhlemeier H., \& Hemker, B. (2007). The impact of computer use at home on students' Internet skills. Computers \& Education, 49(2), 460-480.

Looker, E. D., \& Thiessen, V. (2003). Beyond the digital divide in Canadian schools: From access to competency in the use of information technology. Social Science Computer Review, 21, 475-490.

Martinez, M. (1994). Access to information technologies among school-age children: Implications for a democratic society. Journal of the American Society for Information Science, 45, 395-400.

Morgan, A., \& Kennewell, S. (2005). The role of play in the pedagogy of ICT. Education and Information Technologies, 10(3),177-188.

Morocco, C., \& Zorfas, J. (1988). Technology and transformation: A naturalistic study of special students and computers in the middle school. Journal of Special Education Technology, 9, 88-97.

Mulkeen, A. (2003). What can policy makers do to encourage integration of information and communications technology? Evidence from the Irish school system. Technology, Pedagogy and Education, 12(2), 277-294.

Mumtaz, S. (2000). Factors affecting teachers' use of information and communications technology: A review of the literature. Journal of Information Technology for Teacher Education, 9, 319-341.

Nachmias, R., Mioduser, D., \& Shemla, A. (2001). Information and communication technologies usage by students in an Israeli high school: Equity, gender, and inside/ outside school learning issues. Education and Information Technologies, 6(1), 43-53.

Nasser, R. (2005). Method for social scientists to adapt instruments from one culture to another: The case of the Job Descriptive Index. Journal of Social Sciences, 1(4): 
$232-237$.

Pituch, K. A., \& Lee, Y.-k. (2006). The influence of system characteristics on e-learning use. Computers \& Education, 47(2), 222-244.

Richardson, M. S. (2004). The emergence of new intentions in subjective experience: A so$\mathrm{cial} /$ personal constructionist and relational understanding. Journal of Vocational Behavior, 64, 485-198.

Rochelle, J. M., Pea, R. D., Hoadley, C. M., Gordin, D. N., \& Means, B. M. (2000). Changing how and what children learn in school with computer-based technologies. Children and Computer Technology, 10, 76-101.

Romanowski, M., \& Nasser, R. (in press). Critical thinking and Qatar's Education for a New Era: Negotiating possibilities. International Journal of Critical Pedagogy.

Romanowski, M., \& Nasser, R. (2010). Faculty perceptions of academic freedom at a GCC university. Prospects: UNESCO Quarterly Review of Comparative Education, 4O, 481-497.

Sabherwal, R., \& Newman, M. (2003). Persistence and change in system development: A dialectical view. Journal of Information Technology, 18(2), 69-92.

Selim, H. M. (2007). Critical success factors for e-learning acceptance: Confirmatory factor models. International Journal of Technology Marketing 2(2), 157-182.

Sener, J., \& Stover, M. L. (2000). Integrating ALN into an independent study distance education program: NVCC case studies. Journal of Asynchronous Learning Networks, 4(2), 126-144.

Slavin, R. E., Karweit, N. L., \& Madden, N. A. (1989). Effective programs for students at risk. Boston: Allyn \& Bacon.

Snoeyink, R., \& Ertmer, P. (2001). Thrust into technology: How veteran teachers respond. Journal of Educational Technology Systems, 30, 85-111.

Song S.H. (2004). The functions and future directions of e-learning platforms. The Journal of Educational Informationand Media 10, 151-182.

Somekh, B., Haldane, M., Jones, K., Lewin, C., Steadman, S., Scrimshaw, P., Sing, S., Bird, K., Cummings, J., Downing, B., Harber Stuart, T., Jarvis, J., Diane Mavers, D., \& Derek Woodrow, D. (2007). Evaluation of the primary schools' Whiteboard expansion project: Report to the Department for Children, Schools and Families. Coventry: Becta. Retrieved from http://partners.becta.org.uk/uploaddir/downloads/page_documents/research/whiteboards_expansion.pdf

Tabachnick, B. G., \& Fidell, L. S. (2007). Using multivariate statistics (5th ed.). Boston: 
Allyn and Bacon.

Tort, F., Blondel, F.-M., \& Bruillard, É. (2008). Spreadsheet knowledge and skills of French secondary school students. In Roland T. Mittermeir and Maciej M. Syslo (Eds.), Informatics Education - Supporting Computational Thinking. Proceedings of the Third International Conference on Informatics in Secondary Schools - Evolutions and Perspectives, ISSEP, Lecture Notes in Computer Science (LNCS) Vol. 5090, (pp. 305-316). SpringerLink.

Usun, S. (2004). Undergraduate students attitudes on the use of computers in education. Turkish Online Journal of Educational Technology, 3(2), 62-70.

Uzunboylu, H., Ozdamli, F., \& Ozcinar, Z. (2006). An evaluation of open source learning management systems according to learners tools. ERIC Document Reproduction Service No. ED494265.

Vekiri, I. (2010). Boys' and girls' ICT beliefs: Do teachers matter? Computers \& Education, $55,16-23$.

Vekiri, I., \& Chronaki, A. (2008). Gender issues in technology use: Perceived social support, computer self-efficacy and value beliefs, and computer use beyond school. Computers \& Education, 51, 1392-1404.

Walsham, G., \& Sahay, S. (2006). Research on information systems in developing countries: Current landscape and future prospects. Information Technology for Development, 12(1), 7-24.

Watson, W. R., \& Watson, S. L. (2007). An argument for clarity: What are learning management systems, what are they not, and what should they become? Tech Trends, 51(2), 28-34.

Yin, R. K. (2003). Case study research design and methods. Thousand Oaks, CA: Sage Publications.

\section{Athabasca University $\mathbf{A}$}

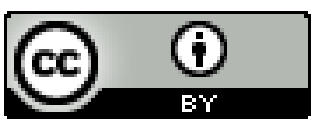

